\title{
Influence of Thermal Design performance of Envelope structure on Indoor Thermal Environment in Dry-Hot and Dry-Cold areas
}

\author{
Chen Jie, Luo Zhixing and Yang Liu \\ School of Architecture, Xi' an University of Architecture and Technology, Xi' an 710055, China
}

\begin{abstract}
Thermal performance is considered to be a key measure in building sustainability. One of the technologies used in the current building sustainable design is the high thermal mass techniques. The application of this type of technology is widely used in traditional architecture. The paper aims at studying the effect of both high thermal insulation and high thermal mass techniques in buildings dynamic behaviour in Dry-Hot and Dry-Cold Climate. The two techniques can lead to conflicting requirements when considering winter and summer conditions. Therefore, it is necessary to identify insulation measures that conserve the mass dynamic behavior. Experimental investigations were carried out on a single - family house to characterize the behavior of one room with high thermal mass in different seasons. Thermal simulations made it possible to explore different retrofit configurations. Different thermal mass and thermal insulation were compared on internal surface temperature. The analysis shows that the most suitable intervention is both high thermal insulation and high thermal mass techniques, and the decrease of the absorption coefficient of the outer surface is beneficial to improve the overall level of solar radiation.
\end{abstract}

\section{Introduction}

The energy consumption of building heating in cold areas accounts for a large proportion of the total energy consumption of buildings, but the fastest growing in building energy consumption is the cooling demand, especially in dry and cold dry and hot climate areas, and the cooling demand is much larger than in other cold areas. the energy saving standard for building heating in cold areas aims to reduce the heat loss of buildings through enclosure structures. the effect of the minimum thermal resistance applied in the standard on the cooling of buildings in summer is often ignored. Aiming at the thermal insulation technology of enclosure structure, such as increasing heat insulation and optimizing solar energy gain, the ultimate goal of improving indoor thermal comfort of buildings can be achieved [1]. Therefore, it is necessary to deal with dry heat and dry cooling. The regional climate characteristics, especially the seasonal differences of solar radiation, are discussed under different heat demand conditions for the heat storage and insulation of enclosure structures. The research on the thermal insulation performance of enclosure structure mainly focuses on the influence of construction mode on the thermal performance of envelope structure. [2-4]. And the optimal thermal design of heat storage and elimination of summer overheat balance in winter [5-7]. And the heat storage and heat transfer of composite walls composed of different material layers [8,9]. Analysis of applicability of heat storage insulation technology under outdoor climate difference [10].

\section{Material and Methods}

In stable heat transfer, the amount of heat transfer, surface temperature, internal temperature and the thermal conductivity of the material and the heat transfer resistance of the structure should be coordinated with the thermal conductivity of the material and the heat transfer resistance of the structure. It is closely related. In the process of periodic heat transfer under harmonic heat, it is related to the heat storage coefficient of material and material layer and the thermal inertia of material layer. Three kinds of heat storage materials are selected according to the heat storage performance, and the thermal properties are shown in Table 1. At the same time, the minimum thermal resistance to meet the energy saving standard in cold region is set as group 1(A1,A2,A3), the thickness of insulation layer is relatively increased to group 2(B1,B2,B3), and the inner surface temperature of different regenerators under two kinds of insulation conditions is calculated. The construction mode of enclosure structure is shown in Table 2.

Table 1 Thermal properties of building materials

\begin{tabular}{lllll}
\hline Material & $\lambda / \mathrm{w}(\mathrm{m} \cdot \mathrm{k})^{-1}$ & $\mathrm{P} / \mathrm{kg} \mathrm{m}^{-3}$ & $\mathrm{C} / \mathrm{w} \cdot \mathrm{h}\left(\mathrm{kg} \mathrm{K}^{-1}\right.$ & $\mathrm{S} / \mathrm{w} \mathrm{m}^{-2} \mathrm{k}^{-1}$ \\
\hline $\begin{array}{l}\text { Molded polystyrene board (EPS } \\
\text { board) }\end{array}$ & 0.042 & 30 & 1.38 & 0.36 \\
\hline
\end{tabular}




\begin{tabular}{lllll}
\hline KPI clay porous brick wall & 0.58 & 1400 & 1.05 & 7.88 \\
compacted clay & 1.16 & 2000 & 0.99 & 12.99 \\
steel reinforced concrete & 1.74 & 2500 & 1 & 17.08 \\
\hline
\end{tabular}

Table 2 Exterior wall constructions of different thermal storage buildings

\begin{tabular}{llll}
\hline group & construction & $\bar{D}$ & $\mathrm{R} / \mathrm{m}^{2} \cdot \mathrm{k}^{\cdot} \mathrm{w}^{-1}$ \\
\hline A1 & 80 thick EPS plate 100 thick KPI clay porous brick wall & 2.04 & 2.245 \\
A2 & 80 thick EPS plate 200 thick rammed clay & 2.92 & \\
A3 & 80 thick EPS slab 300 thick reinforced concrete & 3.62 & 2.721 \\
\hline B1 & 100 thick EPS plate 100 thick KPI clay porous brick wall & 2.21 & \\
B2 & 100 thick EPS plate 200 thick rammed clay & 3.09 & 3.79 \\
B3 & 100 thick EPS slab 300 thick reinforced concrete & 3 & \\
\hline
\end{tabular}

\subsection{Thermal environment simulation}

The integrated building performance analysis software IES uses the finite difference heat transfer mathematical model to carry on the dynamic heat transfer analysis, uses the hourly meteorological data typical annual meteorological data (CSWD). External convective heat transfer model select McAdams, solar radiation model select Anisotropic.

The climate in Dry-Hot and Dry-Cold areas belongs to cold in winter and extremely hot in summer, and the seasonal difference of solar radiation intensity is obvious, which is obviously smaller in winter than in summer. Therefore, the climatic conditions in Turpan area $\left(89.20^{\circ} \mathrm{E}\right.$ and $\left.42.93^{\circ} \mathrm{N}\right)$ are taken as the background of simulation and discussion in this paper. A two-story residential building in Turpan area is selected as the research object, the ground floor is one floor, the ground floor is two floors, and the analysis object is the second floor room. The calculation parameters of indoor thermal environment are set according to the Energy Saving Design Standard of Residential buildings in severe Cold and Cold regions JGJ $26 / 2010$. The building model is shown in Fig. 1. As shown. The simulated working conditions are set in Table 3 .

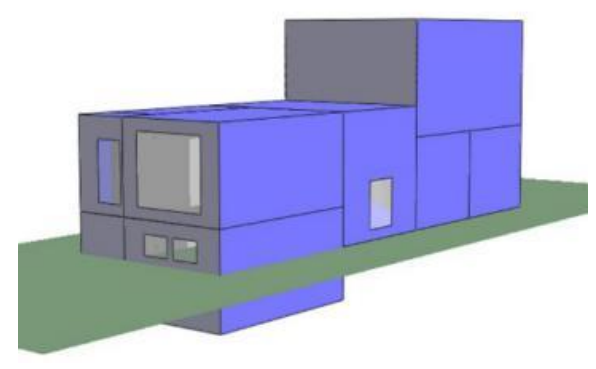

Fig. 1. Residential building model

\section{Results}

\subsection{Inner surface temperature analysis}

Taking the western wall as the research object, the typical diurnal surface temperature analysis is carried out during the hottest period (August 1-August 3), as shown in Fig.2.

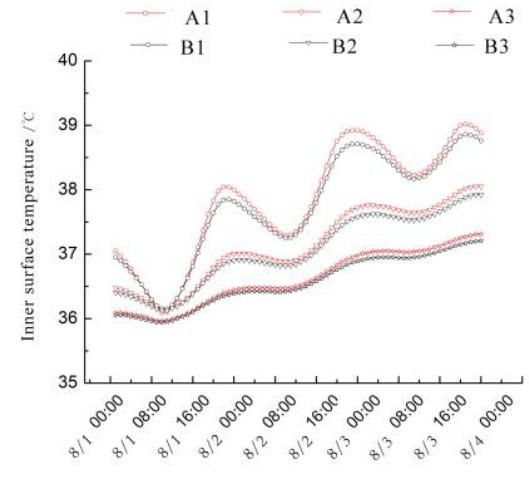

Fig.2 Internal surface temperature of external wall on 1-3, August

At high temperature, the inner surface temperature of high thermal resistance decreases obviously, and the cooling effect of thermal resistance decreases at low temperature at night. With the increase of heat storage, the maximum temperature and amplitude of the inner surface decreased significantly. The effect of heat storage layer on heat attenuation and delay in summer is significantly higher than that in insulation layer. The simulation results are in good agreement with those in reference [10].

\subsection{Analysis of thermal insulation}

The cumulative values of internal surface temperature of six kinds of structures in summer (June-August) and winter (12-February) are calculated. On this basis, in order to describe the effect of thermal insulation and heat insulation of enclosure structure, the cumulative temperature difference change rate is calculated by formula 1 .

$$
\mathrm{V}_{0}=\left(\mathrm{A}_{1}-\mathrm{B}_{1}\right) / \mathrm{A}_{1}
$$




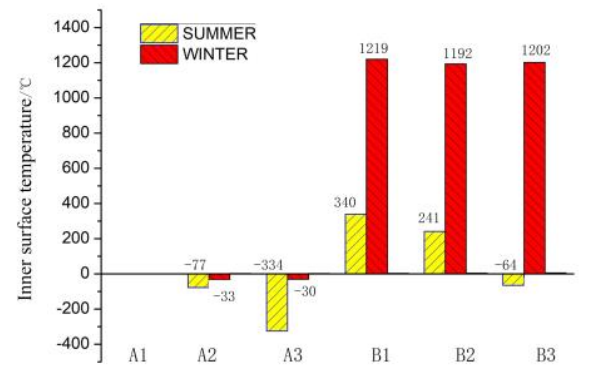

Fig. 3 Accumulated surface temperature difference in winter and summer

the total temperature difference of surface temperature in different heat storage grades in winter is $0.1 \%, 0.6 \%$ in summer and $0.4 \%$ and $0.5 \%$ in summer. Under the same heat storage condition, the inner surface temperature of increasing thermal resistance in winter is increased by $4.10 \% \sim 4.15 \%$, but the inner surface temperature in summer is also increased by $0.33 \% \sim 0.42 \%$. Therefore, due to the dynamic change of indoor and outdoor temperature difference caused by daily difference, there is a critical value of thermal resistance in thermal insulation design of natural cooling buildings in Dry-Hot and Dry-Cold areas.

\subsection{Influence of absorption coefficient of solar radiation.}

Under the condition of the outer surfaces are coated with reflective thermal insulation coating $(\beta=0.48)$, ordinary white coating $(\beta=0.65)$ and uncoated coating $(\beta=0.73)$. The variation of heat gain of envelope structure in winter and summer under different solar radiation absorptivity of external wall is analyzed, as shown in Fig. 4.

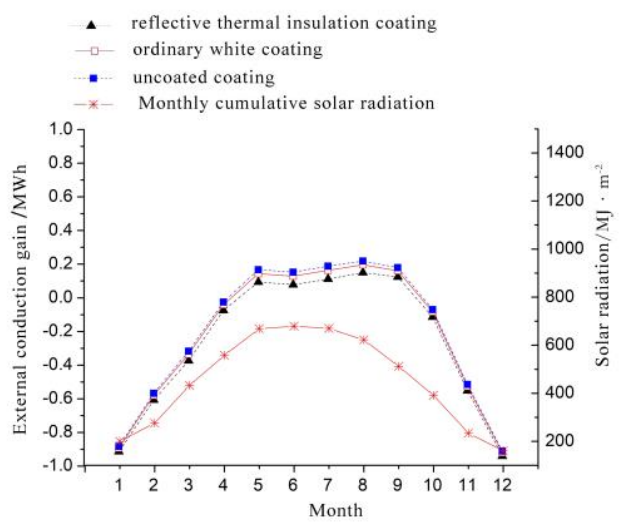

Fig. 4 Heat gain of enclosure with different solar absorptance

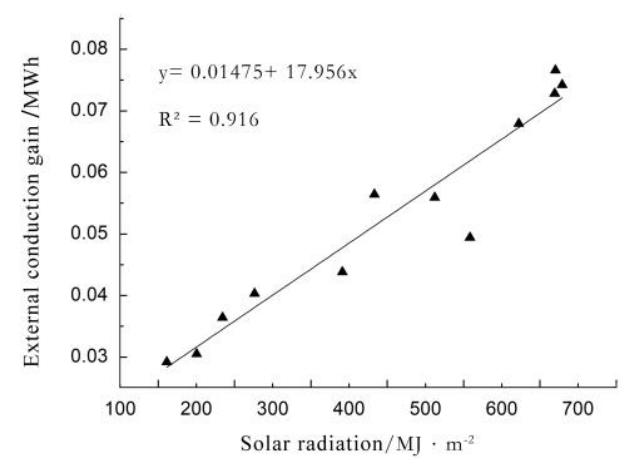

Fig .5 The influence of solar radiation on heat gain of enclosure structure

With the increase of absorptivity, the average heat gain of enclosure structure in summer is $0.11,0.16$, $0.18 \mathrm{MWh}$. the heat difference of envelope structure in winter is $0.74,0.72$, the average difference of $0.71 \mathrm{MWh}$, is less than $0.002 \mathrm{MWh}$, and the effect of radiation absorption coefficient on summer heat gain is greater than that in winter. Monthly cumulative solar radiation in Turpan area averages 657.0 in summer, winter average 212.3 The seasonal difference of solar radiation is large. The periodic heat input caused by solar radiation is studied. as shown in Fig .5, the monthly average heat difference between envelope structure and solar radiation is shown in Fig .5. The monthly cumulative radiation was significantly correlated $\left(\mathrm{R}^{2}=0.916\right)$.

\section{Discussion}

This article under the dry climate dry and cold to heat storage and heat insulation literature [5] results are in agreement with the simulation results, proved that the adiabatic part can prevent heat dissipation, in turn, has brought the increase of building energy consumption, analysis the influence of the climate type differences on the results, the diurnal range to meet using regenerative energy saving performance region, thermal resistance should be paid attention to the adverse impact of regenerative energy saving. Reducing the heat loss of the envelope in winter by increasing the thermal resistance of the envelope is the basis of the insulation design of buildings in cold areas.

\section{Conclusions}

The effects of insulation layer on thermal performance of enclosure structure and solar radiation absorption coefficient on indoor thermal environment under different heat storage levels were analyzed by simulation method.

1) Under the same heat storage conditions, improving the thermal insulation performance of the enclosure structure can raise the temperature of the inner surface in winter, and at the same time cause the temperature of the inner surface to rise in summer, which has a negative effect on the cooling in summer. 2) under the same thermal resistance, improving the heat storage performance of enclosure structure can reduce the inner 
surface temperature in summer, but the inner surface temperature does not change much in winter. Priority should be given to heat storage in dry and dry cold areas. 3 ) the effect of radiation absorptivity on the thermal yield of enclosure structure in summer is greater than that in winter, In the dry-hot and dry-cold areas where the seasonal difference of solar radiation was large, the decrease of the absorption coefficient of the outer surface was beneficial to improve the overall thermal environment level of the building.

\section{Acknowledgement}

This research was funded by National key R \& D Project "Research on basic parameters of Building Energy Saving Design" (2018YFC0704500)

\section{References}

1. L.Yang, Y.Jingjing, S.Bing. Chinese Science Bulletin. 60 (2015)

2. S.A. Al-Sanea, M.F.Zedan. Appl. Energy. 88(2011)

3. Kumbaroğlu G, Madlener R. Energy and Buildings. 49(2012)

4. M .Ozel. Energy and Buildings. 72(2014)

5. A .Reilly, O .Kinnane. Appl. Energy. 198(2017)

6. P. T. Tsilingiris.Energy and Buildings.38(2006)

7. F.Stazi, C.Bonfigli, E. Tomassoni, et al. Energy and Buildings.88(2015)

8. H.Asan. Energy and Buildings. 28(1998)

9. L.Yang, H. Liqiang, L. Jiang. Acta Energ. Sol. Sin.39(2018)

10. Z.Y1lmaz. Energy and Buildings.39(2007) 